\title{
Preparation and Characterization of MMT Doped PVA/SA Polymer Composites
}

\author{
Kapanigowda Hemalatha', Hanumanthappa Somashekarappa ${ }^{1}$, Rudrappa Somashekar ${ }^{*}$ \\ ${ }^{1}$ Department of Physics, Yuvaraja's College, University of Mysore, Mysore, India \\ ${ }^{2}$ Department of Studies in Physics, University of Mysore, Mysore, India \\ Email: ${ }^{*}$ ss@physics.uni-mysore.ac.in
}

Received 20 July 2014; revised 6 September 2014; accepted 19 September 2014

Copyright (C) 2014 by authors and Scientific Research Publishing Inc.

This work is licensed under the Creative Commons Attribution International License (CC BY). http://creativecommons.org/licenses/by/4.0/

c) (i) Open Access

\begin{abstract}
Blends of PVA/SA polymer doped with Montmorillonite were prepared by solution casting technique. Doping of nanoparticles to the polymer matrix does affect the structural and conducting properties. To analyze such changes, these films were subjected to X-ray diffraction, FT-IR spectroscopy, UV-visible absorbance and impedance analysis. Microstructural parameters were computed using in-house program employing X-ray data. Electrical conductivity of these polymer composites was derived using obtained impedance values to understand the conducting property. The results thus obtained are reported in this work.
\end{abstract}

\section{Keywords}

Polymer Composites, X-Ray Diffraction, Nanoferrites

\section{Introduction}

Polymer blending is one of the most important contemporary ways for the development of new polymeric materials. It is a useful technique for designing materials with a wide variety of properties [1]. The structural, optical, thermal and electrical properties of blends can be suitably modified by the addition of dopant depending on their reactivity with the host matrix [2]. It enfolds the advantage of both polymer and filler components leading to a wide spectrum of applications [3]-[5]. Nano composites have a significant role in tailoring the properties of polymeric materials to suit any technology [6] [7]. PVA is a water soluble polymer which is in widespread use in several interesting physical properties and very useful in technical applications in biochemical and medical. PVA is a potential material having a good charge storage capacity and dopant-dependent electrical and optical properties [8] [9]. PVA has the different internal structure which may be considered as amorphous or semi crys-

\footnotetext{
"Corresponding author.
}

How to cite this paper: Hemalatha, K., Somashekarappa, H. and Somashekar, R. (2014) Preparation and Characterization of MMT Doped PVA/SA Polymer Composites. Advances in Materials Physics and Chemistry, 4, 172-178. 
talline. The semi crystalline structure of PVA shows an important feature rather than the amorphous one [10]. Polyvinyl alcohol (PVA) is a transparent, water-soluble and biodegradable polymer with many technological, pharmaceutical and biomedical applications [11]-[13]. Sodium alginate (SA), a biodegradable polymer, is a negatively charged polysaccharide derived from brown sea weed [14]. The unique properties of sodium alginate are its biological origin, non-toxicity, hydrophilicity, biocompatibility and low cost [15] [16]. PVA interacts with SA through hydrogen bonds to form PVA/SA composite films [17]. Important aspects of these PVA/SA films are quite smooth, uniform, flexible, and transparent.

In this work we have doped Montmorillonite (MMT) to PVA/SA polymer blend and characterized the prepared films using various techniques. The obtained results have been quantified in terms of microstructural parameters.

\section{Materials and Methods}

\subsection{Materials}

Montmorillonite (MMT) belongs to soft phyllosilicate group of minerals. Chemically it is Hydrated sodium calcium aluminium magnesium silicate hydroxide $(\mathrm{Na}, \mathrm{Ca})_{0.33}(\mathrm{Al}, \mathrm{Mg})_{2}\left(\mathrm{Si}_{4} \mathrm{O}_{10}\right)(\mathrm{OH})_{2} \mathrm{nH}_{2} \mathrm{O}$. Polyvinyl alcohol (PVA)- $\left[\mathrm{CH}_{2} \mathrm{CH}(\mathrm{OH})\right]_{\mathrm{n}}$ is a semi crystalline material. It has dopant-dependent optical, electrical and thermal properties. Sodium alginate (SA)- $\left[\mathrm{C}_{6} \mathrm{H}_{7} \mathrm{NaO}_{6}\right]_{\mathrm{n}}$ is a non-toxic, hydrophilic, biocompatible, biodegradable and low cost material.

\subsection{Preparation of MMT Doped PVA/SA Films}

Samples were prepared using solution casting method. 5\% PVA solution and 1.5\% SA solution was prepared by dissolving the requisite quantity in $500 \mathrm{ml}$ distilled water using a magnetic stirrer. Different concentrations of PVA/SA solutions (10/90 to 90/10) were mixed and stirred for 2 hours. Later the solution is casted on plastic petri dishes and allowed to dry completely at room temperature. After complete drying, the films were peeled out. The film with 70/30 concentration was found to be blended well, hence the solution of this percentage is used to prepare the different weight concentrations of MMT doped PVA/SA films and used for further studies.

\section{Experimental}

\subsection{X-Ray Diffraction Studies}

XRD patterns of pure PVA/SA and MMT doped PVA/SA films of different concentrations were recorded using Rigaku Miniflex II Desktop X-ray Diffractometer equipped with $\mathrm{CuK}_{\alpha}$ radiation (wavelength $=1.5406 \AA$ ) and a graphite monochromator. The samples were scanned in the $2 \theta$ range $6^{\circ}-60^{\circ}$ and the specifications used for the recording are $30 \mathrm{kV}$ and $15 \mathrm{~mA}$ with $5 \%$ min. The recorded XRD patterns of the films are shown in Figure 1.

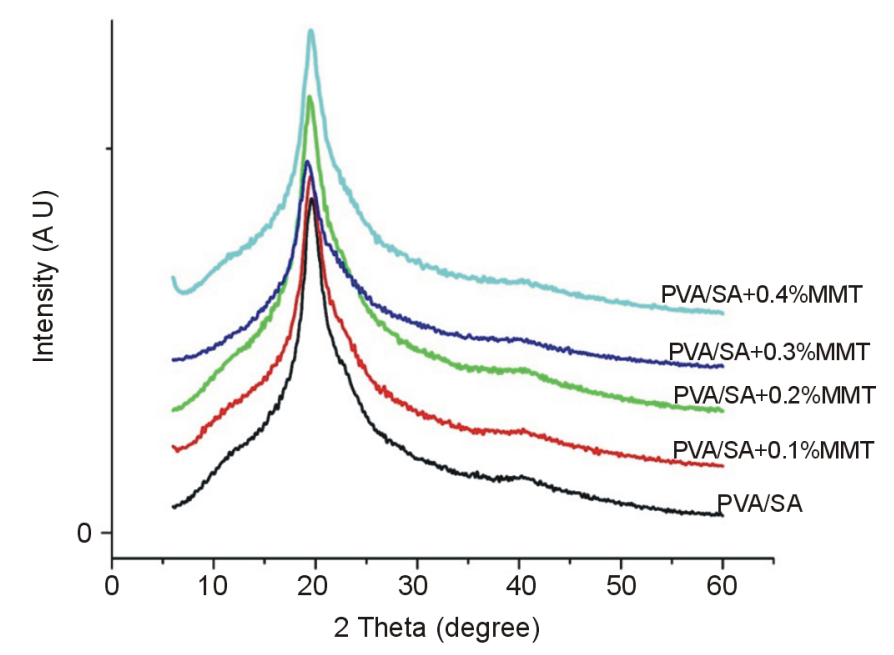

Figure 1. X-ray diffraction patterns of MMT doped PVA/SA films. 


\subsection{Impedance Measurements}

The impedance and phase angle of these polymer samples were measured in the frequency range between $5 \mathrm{~Hz}$ 500 kHz using Electrochemical Impedance Spectroscopy (ZAHNER) IM6.

\subsection{Ultraviolet and Visible Spectroscopic Studies}

The variation of transmittance $(T)$ as a function of wavelength $(\lambda)$ for PVA/SA and PVA/SA: MMT $(0.1 \%$ 0.4\%) was recorded at room temperature using Labtronics MODEL LT-2800 double beam UV-visible spectrophotometer. The recorded UV-visible spectra of the MMT doped PVA/SA films patterns of the films are as shown in Figure 2.

\subsection{FTIR Studies}

The Infrared transmission spectra of these polymer samples were recorded at room temperature in the range of $4000-500 \mathrm{~cm}^{-1}$ using Perkin Elmer Spectrum. The recorded FTIR spectra of pure and MMT doped PVA/SA films are given in Figure 3.

\section{Results and Discussion}

\subsection{X-Ray Diffraction Studies}

X-ray diffraction patterns do indicate the presence of crystalline and amorphous regions. The total strain in crystal is due to lattice mismatch between the material and the substrate and other crystallographic defects that may be present in the crystal. If the size and strain broadening are present simultaneously then crystallite size and strain may be obtained from Williamson-Hall plot [18] [19]. The slope of the plot represents the average strain in the crystal whereas the intercept gives the crystalline size according to the relation.

$$
\beta \frac{\cos \theta}{\lambda}=\frac{1}{D}+4 \varepsilon \frac{\sin \theta}{\lambda}
$$

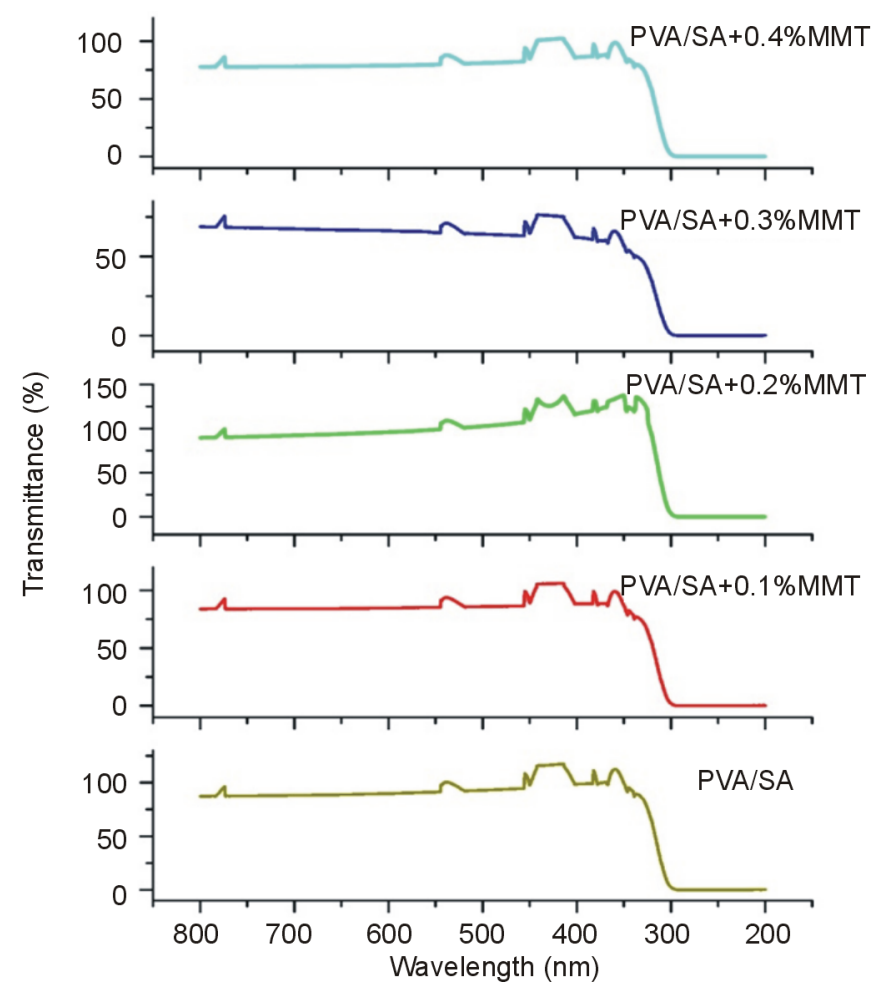

Figure 2. UV-visible spectra of MMT doped PVA/SA films. 


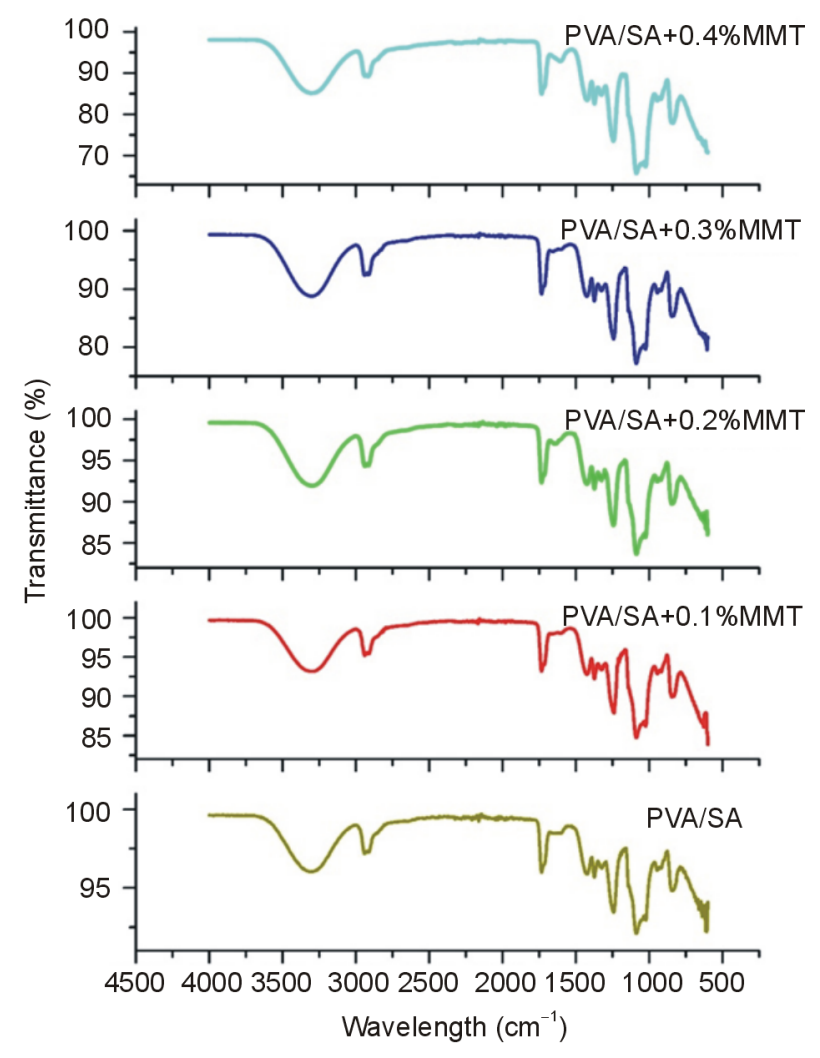

Figure 3. FTIR spectra of pure and MMT doped PVA/SA films.

where $\beta$ is Full Width at Half Maxima (FWHM), $D$ is the average crystallite size and $\varepsilon$ is average strain. Plot of $\beta \frac{\cos \theta}{\lambda}$ verses $\frac{\sin \theta}{\lambda}$ gives a straight line with y intercept equal to the inverse of the size and the slope equal to the micro strain present in a given sample.

This approximated method makes it possible to obtain a qualitative mean value characterizing each of the effects that cause the increase in peak width. If the slope of the line is almost horizontal, then the sample contains only a small amount of micro strains. On an average, we observed that the crystallite size of pure polymer blend to be decreased with the increase in dopant concentration. This is because of the nanoparticles which make the polymer blend more amorphous with concentration. Since the added concentration of the nanoparticle is very small it does not show any prominent reflections in the XRD patterns but it effects internally in the broadening of obtained reflection for pure polymer blend and thus results in the decrease of overall crystallite size of the parent polymer matrix. Microstructural parameters of these pure PVA/SA and PVA/SA: MMT composites MMT are given in the Table 1.

\subsection{Conductivity Measurements}

Prepared films of known thickness " $d$ " were placed between the electrodes of known area " $A$ " of a.c. impedance spectrometer. The bulk resistance $R_{b}$ of the film is calculated using the relation $R_{b}=Z \cos \theta$ [20], where $Z$ is impedance and $\theta$ is the phase angle. Ionic conductivity " $S$ " of the polymer sample is calculated using the relation.

$$
S=\frac{1}{R_{b}} \frac{d}{A}
$$

Impedance, bulk resistance and conductivity of pure PVA/SA and PVA/SA films doped with different concentrations of MMT are given in the Table 2. From Table 2, we observed that the conductivity increases with 
Table 1. Microstructural parameters of MMT doped PVA/SA films.

\begin{tabular}{ccc}
\hline Sample & \multicolumn{2}{c}{ Microstructural parameters } \\
\cline { 2 - 3 } & Crystallite size in $\AA$ & Lattice strain in \% \\
\hline Pure PVA/SA & $62.8 \pm 0.1$ & $6.7 \pm 0.7$ \\
PVA/SA + 0.1\% MMT & $56.4 \pm 0.1$ & $7.2 \pm 0.1$ \\
PVA/SA + 0.2\% MMT & $51.7 \pm 0.1$ & $7.9 \pm 0.2$ \\
PVA/SA + 0.3\% MMT & $48.8 \pm 0.1$ & $8.7 \pm 0.3$ \\
\hline
\end{tabular}

Table 2. Impendance, bulk resistance and conductivity of the MMT doped PVA/SA films.

\begin{tabular}{cccccc}
\hline Concentration (\%) & $\begin{array}{c}\text { Thickness } \\
d(\mathrm{~mm})\end{array}$ & $\begin{array}{c}Z \\
\mathrm{E}+06(\Omega)\end{array}$ & $\theta$ (degree) & $\begin{array}{c}\text { Bulk resistance } R_{b} \\
\mathrm{E}+06(\Omega)\end{array}$ & $\begin{array}{c}\text { Conductivity } S \\
\mathrm{E}-08\left(\Omega^{-1} \mathrm{~m}^{-1}\right)\end{array}$ \\
\hline Pure PVA/SA & 0.14 & $7.32 \pm 0.86$ & $74.4 \pm 1.21$ & $4.15 \pm 0.49$ & $4.77 \pm 0.57$ \\
$0.1 \% \mathrm{MMT}+$ PVA/SA & 0.14 & $5.12 \pm 0.86$ & $76.1 \pm 2.89$ & $3.86 \pm 0.65$ & $5.13 \pm 0.89$ \\
$0.2 \% \mathrm{MMT}+$ PVA/SA & 0.17 & $6.28 \pm 0.83$ & $80.7 \pm 3.28$ & $3.46 \pm 0.45$ & $6.95 \pm 0.93$ \\
$0.3 \% \mathrm{MMT}+$ PVA/SA & 0.16 & $5.37 \pm 0.91$ & $71.3 \pm 1.63$ & $3.14 \pm 0.53$ & $7.21 \pm 1.27$ \\
$0.4 \% \mathrm{MMT}+$ PVA/SA & 0.13 & $4.92 \pm 0.92$ & $71.2 \pm 1.70$ & $2.35 \pm 0.43$ & $7.84 \pm 1.52$ \\
\hline
\end{tabular}

increase in the concentrations of MMT. A least squares plot of $\sigma$ vs $S_{0} \mathrm{e}^{(-C * S)}$ gives a value of $S$ as $9.6 \%$. Here $S$ represents fractional change in interfacial surface area value with the surrounding polymer network. There is a net increase of 9.6\% of interfacial surface area of MMT with PVA/SA network. This is significant which indicates the changes in the physical as well as environmental properties of the composite.

\subsection{Ultraviolet and Visible Spectroscopic Studies}

A casual glance at Figure 2 indicates that PVA/SA has high transmission and it decreases with the increase in concentration of MMT in doped films. Further, it is interesting to note that these films have absorption at wavelength which corresponds to the energy of $1 \mathrm{eV}$ which indicates in a way that these films do behave as if there is an energy gap similar to those in semiconductors. This value decreases with increase in concentration of MMT. This is due to the formation of intermolecular hydrogen bonding between the ions of the dopant and the $\mathrm{OH}$ groups. The decrease in transmission for doped PVA/SA films reflects the variation in the optical band gap which arises due to the change in polymer structure. Also it is found that as the concentration of MMT increases the transmittance edge shifts towards the lower wavelength region $(773 \mathrm{~nm}$ to $769 \mathrm{~nm}$ ).

\subsection{FT-IR Studies}

The spectra exhibit bands characteristic of stretching and bending vibrations of the films. FT-IR absorption bands positions and the assignments of all the prepared samples are listed in Table 3. From the spectra, for pure PVA/SA the broad band at about $3309 \mathrm{~cm}^{-1}$ is assigned to $\mathrm{O}-\mathrm{H}$ stretching vibration of hydroxyl group. SA is anionic polysaccharide with a carboxylate group in the side chain. This makes it a good biocompatible and biodegradable. Hydrogen bonding is formed between carboxyl group of SA and hydroxyl group of PVA. The band corresponding to $\mathrm{CH}$ asymmetric stretching vibration occurs at about $2914 \mathrm{~cm}^{-1}$. The band at about $1086 \mathrm{~cm}^{-1}$ corresponds to C-O stretching of acetyl groups present on the PVA backbone. The vibrational band at about $1734 \mathrm{~cm}^{-1}$ corresponds to $\mathrm{C}=\mathrm{O}$ stretching of PVA and SA [21] [22]. The band at about $836 \mathrm{~cm}^{-1}$ is attributed to AlMgOH bending vibrations [23]. In the case of MMT filled PVA/SA, FR-IR spectra shows shifts in some bands $\left(1423 \mathrm{~cm}^{-1}, 1243 \mathrm{~cm}^{-1}\right.$ and $\left.1086 \mathrm{~cm}^{-1}\right)$ which is essentially due to Si-O stretching: out of plane and in-plane which is absent in pure films. Some shift is observed here in these films due to constraints of neighbouring polymer network. $1423 \mathrm{~cm}^{-1}$ is normally assigned to carboxyl group. This indicates the considerable interaction between the polymer and dopant. Addition of $4 \%$ of MMA, Si-O-Si with anti symmetric stretching mode is visible around $1100 \mathrm{~cm}^{-1}$. In pure PVA/SA, the intensity is around 90 , and then it changes to $85(0.1 \%$ of MMT), less than 85 (0.2\% of MMT), less than 80 (0.3\% of MMT) and less than 70 (0.4\% of MMT). Obviously this stretching has been damped by the interface surrounding MMT in polymer network. 
Table 3. Assignment of IR characterising peaks for prepared MMT doped PVA/SA films.

\begin{tabular}{cc}
\hline Vibrational frequency $\left(\mathrm{cm}^{-1}\right)$ & Band assignment \\
\hline 3309 & O-H stretching \\
2914 & C-H stretching \\
1734 & C=O stretching \\
1423 & C-H bend \\
1243 & C-N stretching \\
1086 & C-O stretching \\
837 & AlMgOH bending \\
\hline
\end{tabular}

\section{Conclusion}

Preparation and characterization of PVA/SA films have shown interesting results like conductivity, transparency and energy gap. The increase in concentration of MMT nanoparticles, increases the conductivity of nanocomposite by decreasing the energy gap. This is in conformity with the variation of microstructural parameters computed from X-ray line profile analysis. Reason for such a change in the parameters of these polymers is due to the formation of hydrogen bonding between PVA and SA. In fact such bonding alters the polymer network and hence crystallite size. It is important to note that these changes are due to fractional change in interfacial surface area of about $9.6 \%$ which has been computed using conductivity data. Further, FTIR analysis shows that the band at about $836 \mathrm{~cm}^{-1}$ is attributed to AlMgOH bending vibrations. In the case of MMT filled PVA/SA, FT-IR spectra show that shifts in some bands $\left(1423 \mathrm{~cm}^{-1}, 1243 \mathrm{~cm}^{-1}\right.$ and $\left.1086 \mathrm{~cm}^{-1}\right)$ are essentially due to Si-O stretching, which plays a significant role in the final property of the composite.

\section{Acknowledgements}

Mrs K.H.L thanks UGC for providing fellowship for this research under Faculty Improvement Program. Authors thank UGC, India for grants in the form of UPE/CPEPA projects. Thejas Urs G and Dr Mahadevaiah's help in preparing the samples and manuscript is acknowledged.

\section{References}

[1] Utracki, L.A. and Favis, B.D. (1989) Polymer Alloys and Blends. In: Cheremisinoff, N.P., Ed., Hand Book of Polymer Science and Technology, Vol. 4, Marcel Dekker, New York, 121-202.

[2] Toutanji, H. and Ortiz, G. (2001) The Effect of Surface Preparation on the Bond Interface between FRP Sheets and Concrete Members. Composite Structures, 53, 457-462. http://dx.doi.org/10.1016/S0263-8223(01)00057-5

[3] Zhu, J., Uhl, F.M., Morgan, A.B. and Wilkie, C.A. (2001) Studies on the Mechanism by Which the Formation of Nanocomposites Enhances Thermal Stability. Chemistry of Materials, 13, 4649-4654. http://dx.doi.org/10.1021/cm010451y

[4] Huynh, W.U., Dittmer, J.J. and Alivisatos, A.P. (2002) Hybrid Nanorod-Polymer Solar Cells. Science, 295, $2425-2427$. http://dx.doi.org/10.1126/science.1069156

[5] Brosseau, C., Queffelec, P. and Talbot, P. (2001) Microwave Characterization of Filled Polymers. Journal of Applied Physics, 89, 4532-4540. http://dx.doi.org/10.1063/1.1343521

[6] Beecroft, L.L. and Ober, C.K. (1997) Nanocomposite Materials for Optical Applications. Chemistry of Materials, 9, 1302-1317. http://dx.doi.org/10.1021/cm960441a

[7] Kumar, R.V., Elgamiel, R., Diamant, Y., Gedanken, A. and Norwig, J. (2001) Sonochemical Preparation and Characterization of Nanocrystalline Copper Oxide Embedded in Poly(Vinyl Alcohol) and Its Effect on Crystal Growth of Copper Oxide. Langmuir, 17, 1406-1410. http://dx.doi.org/10.1021/la001331s

[8] Devi, C.U., Sharma, A.K. and Rao, V.V.R.V. (2002) Electrical and Optical Properties of Pure and Silver NitrateDoped Polyvinyl Alcohol Films. Materials Letters, 56, 167. http://dx.doi.org/10.1016/S0167-577X(02)00434-2

[9] Thejas Urs, G., Nanda Prakash, M.B., Ananda, H.T. and Somashekar, R. (2014) Radial Distribution Studies on Water Soluble Polymers Using XRD Line Profile Data. Solid State Physics, AIP Conference Proceedings, 1591, 170-171.

[10] Nanda Prakash, M.B., Thejas Urs, G., Anand, H.T. and Somashekar, R. (2014) Pair Correlation Studies of CdCl 2 Doped PVA Polymer Films Using X-Ray Data. Solid State Physics, AIP Conference Proceedings, 1591, 816-818. 
http://dx.doi.org/10.1063/1.4872766

[11] Hassan, C.M. and Peppas, N.A. (2000) Structure and Applications of Poly(Vinyl Alcohol) Hydrogels Produced by Conventional Crosslinking or by Freezing/Thawing Methods. Advances in Polymer Science, 153, 37-65. http://dx.doi.org/10.1007/3-540-46414-X_2

[12] Kokabi, M., Sirousazar, M. and Hassan, Z.M. (2007) PVA-Clay Nanocomposite Hydrogels for Wound Dressing. European Polymer Journal, 43, 773-781. http://dx.doi.org/10.1016/j.eurpolymj.2006.11.030

[13] Nagura, M., Hamano, T. and Ishikawa, H. (1989) Structure of Poly(Vinyl Alcohol) Hydrogel Prepared by Repeated Freezing and Melting. Polymer, 30, 762-765. http://dx.doi.org/10.1016/0032-3861(89)90169-9

[14] Bhattarai, N. and Zhang, M. (2007) Controlled Synthesis and Structural Stability of Alginate-Based Nanofibers. Nanotechnology, 18, 455-601. http://dx.doi.org/10.1088/0957-4484/18/45/455601

[15] Sennerby, L., Rostlund, T., Albrektsson, B. and Albrektsson, T. (1987) Acute Tissue Reactions to Potassium Alginate with and without Colour/Flavor Additives. Biomaterials, 8, 49-52. http://dx.doi.org/10.1016/0142-9612(87)90029-9

[16] Li, Z.S., Ramay, H.R., Hauch, K.D., Xiao, D. and Zhang, M. (2005) Chitosan Alginate Hybrid Scaffolds for Bone Tissue Engineering. Biomaterials, 26, 3919-3928. http://dx.doi.org/10.1016/j.biomaterials.2004.09.062

[17] Sanderson, R.D., Immelman, E., Bezuidenhout, D., Jacobs, E.P. and Van Reenen, A.J. (1993) Polyvinyl Alcohol and Modified Polyvinyl Alcohol Reverse Osmosis Membranes. Desalination, 90, 15-29. http://dx.doi.org/10.1016/0011-9164(93)80161-F

[18] Somashekar, R., Hall, J.H. and Carr, P.D. (1989) The Determination of Crystal Size and Disorder from X-Ray Diffraction Photographs of Polymer Fibres. 1. The Accuracy of Determination of Fourier Coefficients of the Intensity Profile of a Reflection. Journal of Applied Crystallography, 22, 363-371. http://dx.doi.org/10.1107/S0021889889004085

[19] Hall, J.H. and Somashekar, R. (1991) The Determination of Crystal Size and Disorder from the X-Ray Diffraction Photograph of Polymer Fibres. 2. Modelling Intensity Profiles. Journal of Applied Crystallography, 24, 1051-1059. http://dx.doi.org/10.1107/S0021889891007707

[20] Qian, X.M., Gu, N.Y., Cheng, Z.L., Yang, X.R., Wang, E. and Dong, S.J. (2001) Methods to Study the Ionic Conductivity of Polymeric Electrolytes Using a.c. Impedance Spectroscopy. Journal of Solid State Electrochemistry, 6, 8-15. http://dx.doi.org/10.1007/s100080000190

[21] Abdelaziz, M. and Abdelrazek, E.M. (2007) Effect of Dopant Mixture on Structural, Optical and Electron Spin Resonance Properties of Polyvinyl Alcohol. Physica B, 390, 1-9. http://dx.doi.org/10.1016/j.physb.2006.07.067

[22] Laot, C.M., Marand, E. and Oyama, H.T. (1999) Spectroscopic Characterization of Molecular Inter Diffusion at a Poly(Vinyl Pyrrolidone)/Vinyl Ester Interface. Polymer, 40, 1095-1108. http://dx.doi.org/10.1016/S0032-3861(98)80003-7

[23] Kevadiya, B.D., Patel, H.A., Joshi, G.V., Abdi, S.G.R. and Bajaj, H.C. (2010) Montmorillonite-Alginate Composites as a Drug Delivery System: Intercalation and in Vitro Release of Diclofenac Sodium. Indian Journal of Pharmaceutical Sciences, 72, 732-737. http://dx.doi.org/10.4103/0250-474X.84582 
Scientific Research Publishing (SCIRP) is one of the largest Open Access journal publishers. It is currently publishing more than 200 open access, online, peer-reviewed journals covering a wide range of academic disciplines. SCIRP serves the worldwide academic communities and contributes to the progress and application of science with its publication.

Other selected journals from SCIRP are listed as below. Submit your manuscript to us via either submit@scirp.org or Online Submission Portal.
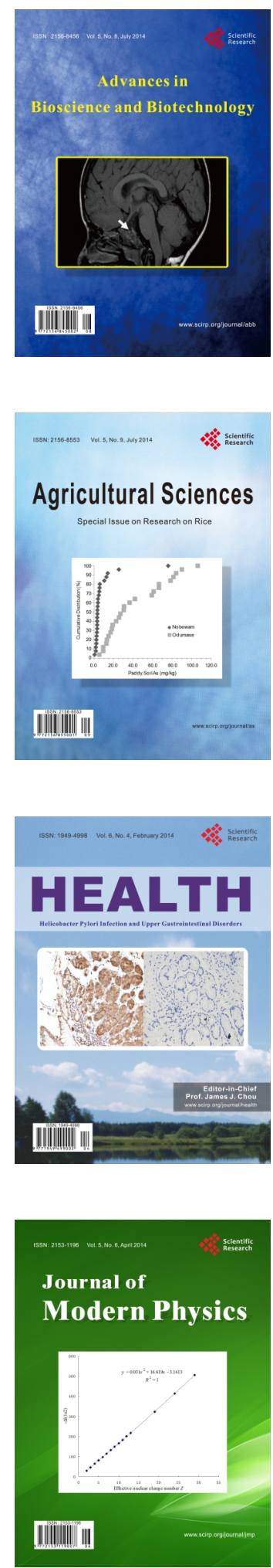
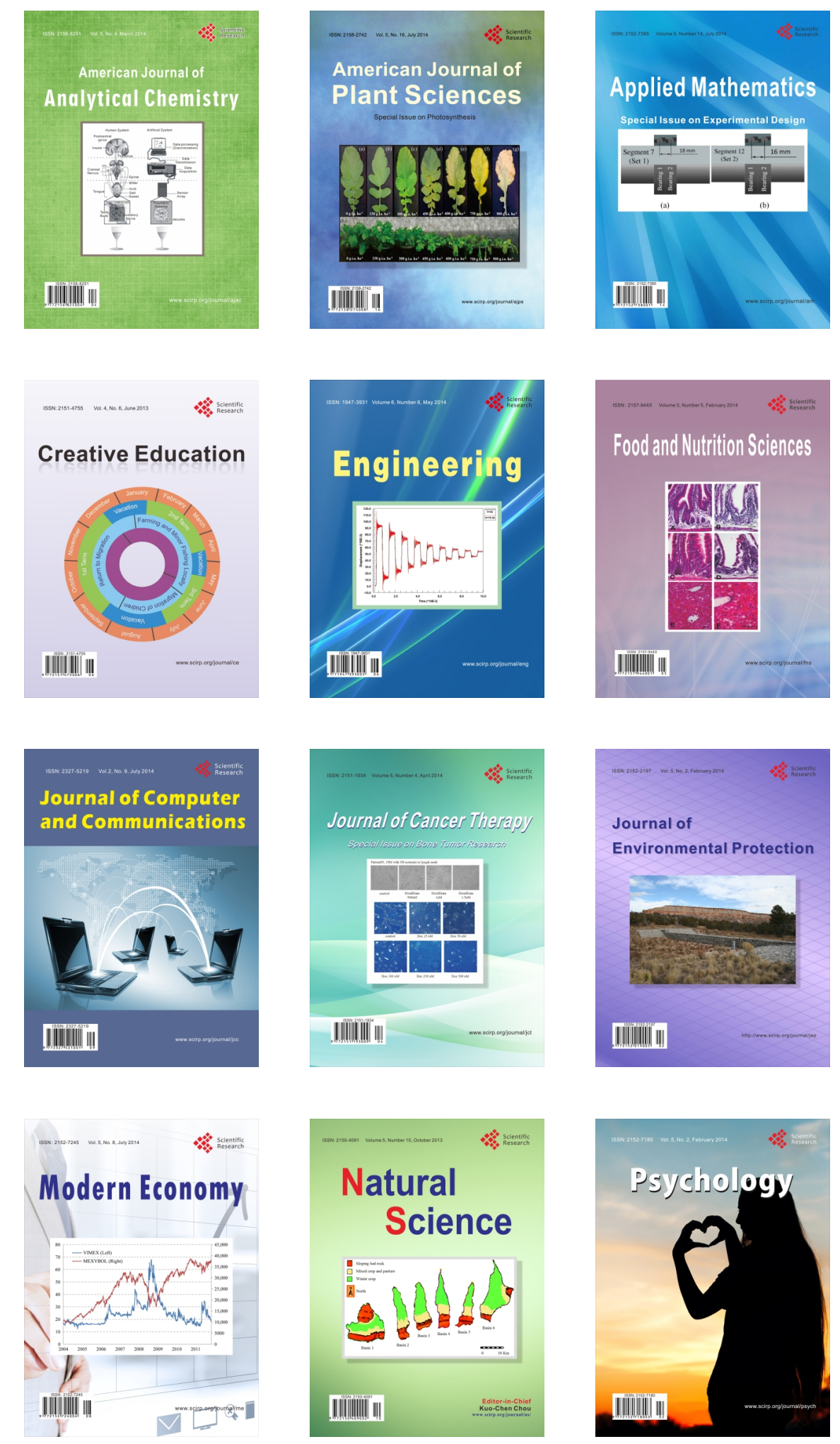